\title{
Synergistic effects of Bifidobacterium thermophilum RBL67 and selected prebiotics on inhibition of Salmonella colonization in the swine proximal colon PolyFermS model
}

Sabine Amani Tanner, Christophe Chassard, Annina Zihler Berner and Christophe Lacroix*

\begin{abstract}
Background: Probiotics and prebiotics are promising strategies to counteract Salmonella prevalence in swine. In the present study, we investigated the effects of prebiotics (fructo- (FOS), galacto- (GOS) and mannan- (MOS) oligosaccharides) and the bacteriocinogenic Bifidobacterium thermophilum RBL67 (RBL67) on Salmonella enterica subsp. enterica serovar Typhimurium N-15 (N-15) colonization using the PolyFerms in vitro continuous fermentation model simulating the swine proximal colon.

Material and methods: The PolyFermS model was designed with a first-stage reactor containing immobilized fecal pig microbiota. This reactor continuously inoculated five parallel second-stage reactors, a control and four treatment reactors, all operated with proximal colon conditions. FOS and GOS (5.2 g/day), and MOS (half dosage) and RBL67 $\left(10^{8}\right.$ copy numbers $/ \mathrm{mL}$ applied daily) were tested on the ability of $\mathrm{N}-15$ to colonize reactors, inoculated with the same microbiota. Reactor effluents were collected daily and analyzed for microbial composition (quantitative PCR and 454 pyrosequencing of 165 rRNA gene pool) and main metabolites (HPLC).

Results: RBL67 and N-15 were shown to stably colonize the system. Colonization of N-15 was strongly inhibited by FOS and GOS, whereas addition of RBL67 alone or combined with MOS showed intermediate results. However, the effect of FOS and GOS was enhanced when prebiotics were combined with a daily addition of RBL67. FOS and GOS increased the total short chain fatty acid production, especially acetate and propionate. RBL67 combined with FOS additionally stimulated butyrate production.

Conclusions: Our study demonstrates the suitability of the porcine PolyFermS in vitro model to study nutritional effects of pro- and prebiotics on gut microbiota composition and activity. It can further be used to monitor Salmonella colonization. The inhibition effects of FOS and GOS on N-15 colonization are partly due to an increased acetate production, while further antimicrobial mechanisms may contribute to an enhanced inhibition with prebiotic-RBL67 combinations. A future direction of this work could be to understand the anti-Salmonella effects of Bifidobacterium thermophilum RBL67 in the presence of prebiotics to unravel the mechanism of this probiotic:pathogen interaction.
\end{abstract}

Keywords: Bifidobacterium thermophilum RBL67, Swine, Intestinal fermentation model, Prebiotics, Probiotics, Salmonella enterica subsp. enterica serovar Typhimurium N-15

\footnotetext{
* Correspondence: christophe.lacroix@hest.ethz.ch

Laboratory of Food Biotechnology, Institute of Food, Nutrition and Health,

Department of Health Science and Technology, ETH Zurich,

Schmelzbergstrasse 7, 8092 Zurich, Switzerland
} 


\section{Background}

Salmonella are highly prevalent in swine where they affect about one third of all production holdings in the European Union [1]. Salmonella negatively impact pig health and the productivity of livestock. Transmission to humans occurs via the food-chain, leading to severe infections. Therefore, Salmonella control must be initiated at the farm level. Since antibiotics for growth promotion have been banned, alternative strategies to improve gut health are necessary to maintain productivity. Gut microbial composition and activity can be directly influenced via the diet [2]. This in turn impacts the colonization ability of enteric pathogens, such as Salmonella, through competitive exclusion mechanisms [3]. Probiotics and prebiotics, known for their potential to modulate gut microbial composition and activity, are amongst the promising alternative strategies [4].

Probiotics are defined as "live microorganisms which, when administered in adequate amounts, confer a health benefit on the host" [5]. Beneficial effects attributed to probiotics in pig feed include reduced incidence and severity of infections and decreased shedding of pathogens [6-8]. For example, weaned pigs treated with a five strain probiotic mixture (four Lactobacillus strains and one Pediococcus strain) showed significantly reduced ( $>2 \log _{10}$ $\mathrm{cfu} / \mathrm{g}$ feces) Salmonella numbers at 15 days post-infection [7]. Other authors report a lower incidence of diarrhea and fecal coliform numbers when feeding Lactobacillus rhamnosus GG [9], reduced carriage of Escherichia coli with Bifidobacterium lactis HN019 [10], or decreased Salmonella counts in feces and tissues after feeding pigs a combination of Lactobacillus acidophilus and Lactobacillus reuteri [8].

Prebiotics are non-digestible food-ingredients that are readily fermentable in the colon and stimulate potentially health-promoting bacteria, mainly bifidobacteria and/or lactobacilli, thereby beneficially shifting the microbial equilibrium of the host gut [11]. For example, Patterson et al. [12] reported stimulation of Bifidobacterium spp. and Lactobacillus spp. with a concomitant suppression of Clostridium spp. and members of Enterobacteriaceae spp. upon feeding of inulin to pigs. Prebiotics can stimulate short chain fatty acid (SCFA) production, known to play a key role in intestinal host health. For example, butyrate, the main energy source for colonocytes, has anti-inflammatory and anti-carcinogenic properties (reviewed by Russell et al. [13]) and down-regulates the expression of genes associated with Salmonella invasion [14]. However, conflicting results have been reported for the effects of prebiotic feeding in pigs. Tzortzis et al. [15] reported higher acetate concentrations and increased bifidobacteria numbers after feeding GOS to pigs, while Mikkelsen and Jensen [16] showed increased butyrate production after feeding FOS to piglets. In contrast, no effect was observed with FOS on bifidobacterial populations [17] and on fecal SCFA concentrations [18]. Prebiotics are increasingly combined with probiotics (synbiotics) to enhance probiotic survival and growth. Synbiotic formulations tested in pigs decreased the level of Enterobacteriaceae in pig fecal samples [19], and reduced adherence of Escherichia coli O8:K88 to the jejunal and colonic mucosa [20]. However, synbiotic formulations have been much less studied for pathogen inhibition. Yet, they have a promising potential considering the competitive advantage of the probiotic through simultaneous application of a prebiotic with high specificity [21,22].

The species $B$. thermophilum belongs to the commensals of the pig gut microbiota [23]. Bifidobacterium thermophilum RBL67 (RBL67) previously isolated from baby feces was shown to produce a bacteriocin-like substance (BLIS) with in vitro activity against Listeria and Salmonella [24-26]. Furthermore, we recently showed that RBL67 has antagonistic effects on Salmonella infection in an in vitro continuous intestinal fermentation model simulating the child proximal colon [27]. This strain was reported to adhere to human intestinal cell lines [28] and to exert protective effects on epithelial HT29-MTX cell culture integrity upon Salmonella challenge in combined cellular and colonic fermentation models [29]. Inulin supplemented in a threestage continuous intestinal fermentation model of the child induced an increase of $B$. thermophilum numbers in the proximal, transverse and distal colon sections while SCFA production was shifted towards higher butyrate concentrations [30]. However, inulin in the proximal colon environment of the model was also shown to promote Salmonella growth [30], and to increase the efficiency of HT29-MTX cell invasion [29]. Finally, RBL67 has technological features of interest for application, such as being moderately oxygen-tolerant, growing at high cell density, low $\mathrm{pH}$ and high temperatures of up to $47^{\circ} \mathrm{C}$ [31].

Studying the complex interplay of pro- and prebiotics with the gut microbiota and pathogens is hindered by the inaccessibility of the gastrointestinal tract. Studies are further challenged by ethical limits to conduct in vivo animal infection trials. In this context, in vitro models represent a cost-effective and ethically less constraint strategy [32]. We recently reported and validated a novel two-stage in vitro continuous fermentation model (PolyFermS) inoculated with immobilized fecal microbiota simulating the swine proximal colon. This model allows the parallel operation of five self-contained independent fermentations to simultaneously test different nutritional factors with the same microbiota [33]. In this study, we used this PolyFermS model of the swine proximal colon to investigate the effects of B. thermophilum RBL67 and prebiotics (FOS, GOS and MOS) on the gut microbiota composition and activity and on the colonization of the enteric pathogen Salmonella enterica subsp. enterica serovar Typhimurium N-15 (N-15). 


\section{Results}

\section{Colonization potential of RBL67 and N-15}

To evaluate the colonization ability of RBL67 and N-15 in an in vitro model of the swine proximal colon, we inoculated TRs once with RBL67 with and without FOS or with N-15 during period 1 (Figure 1). RBL67 and N-15 concentrations were estimated $96 \mathrm{~h}$ after addition and data were compared to the theoretical washout curve (Figure 2).

The N-15 cell counts initially declined at a rate close to the theoretical washout curve and stabilized after $27 \mathrm{~h}$ at $4.7 \pm 0.2 \log _{10} \mathrm{cfu} / \mathrm{mL}$ until $96 \mathrm{~h}$. RBL67 gene copy numbers $(\mathrm{CN})\left(8.1 \log _{10} \mathrm{CN} / \mathrm{mL}\right)$ declined faster than the theoretical washout curve during the first $54 \mathrm{~h}$ and reached a stable value of $4.6 \pm 0.2 \log _{10} \mathrm{CN} / \mathrm{mL}$ between 78 and $96 \mathrm{~h}$. A similar pattern was observed for the treatment of RBL67 combined with FOS, with CN decreasing until $27 \mathrm{~h}$, followed by stability $\left(5.3 \pm 0.3 \log _{10} \mathrm{CN} / \mathrm{mL}, 27-96 \mathrm{~h}\right)$.

\section{Effect of prebiotics and RBL67 on N-15 colonization}

Pretreatments with RBL67 and prebiotics were tested during periods $2-4$ on $\mathrm{N}-15$. After $\mathrm{N}-15$ infection in period 2 , $\mathrm{N}-15$ cell counts declined $1.6 \log _{10} \mathrm{cfu} / \mathrm{mL}$ during the first 2 days and stabilized at $5.0 \pm 0.2 \log _{10} \mathrm{cfu} / \mathrm{mL}$ effluent (days 2-5) (Figure 3). Unexpectedly, N-15 cell counts in the following periods showed either a limited initial decline phase after the first day of challenge followed by stability $(6.3 \pm$
$0.1 \log _{10} \mathrm{cfu} / \mathrm{mL}$, period 3 , days $1-5$ ), or a steady increase until day 2 to reach $7.4 \pm 0.1 \log _{10} \mathrm{cfu} / \mathrm{mL}$ (period 4 , days $2-5)$. The treatments with FOS and GOS during periods 2 and 3 induced a strong inhibition of N-15 colonization, with $\mathrm{N}-15$ cell numbers decreasing below the detection limit (4.1 $\log _{10} \mathrm{cfu} / \mathrm{mL}$ effluent) 3 days post-infection. When FOS or GOS were combined with RBL67 (R-FOS and R-GOS) during periods 2-4, N-15 counts decreased even more rapidly compared to treatments with the prebiotics alone, reaching non-detectable levels after two days post-infection (periods 2 and 3) or reducing initial N-15 counts by approximately $2 \log _{10} \mathrm{cfu} / \mathrm{mL}$ (period 4 ). Intermediate effects were recorded for RBL67 alone (periods 2 and 3 ) and in combination with MOS (R-MOS, period 4), with a reduction of $\mathrm{N}-15$ counts 2 days post-infection by approximately $1.8 \pm 0.3$ and $0.7 \log _{10} \mathrm{cfu} / \mathrm{mL}$, respectively.

\section{Effect of prebiotics, RBL67 and N-15 infection on gut microbiota composition}

Changes in the microbial community composition were monitored by qPCR and by 454 pyrosequencing. We compared mean copy numbers (days 2-4) of bacterial populations during pseudo-steady states of N-15 challenge periods of control and treatment reactors.

Bacteroides-Prevotella and Clostridium Cluster IV were the most prominent groups, followed by Enterobacteriaceae,

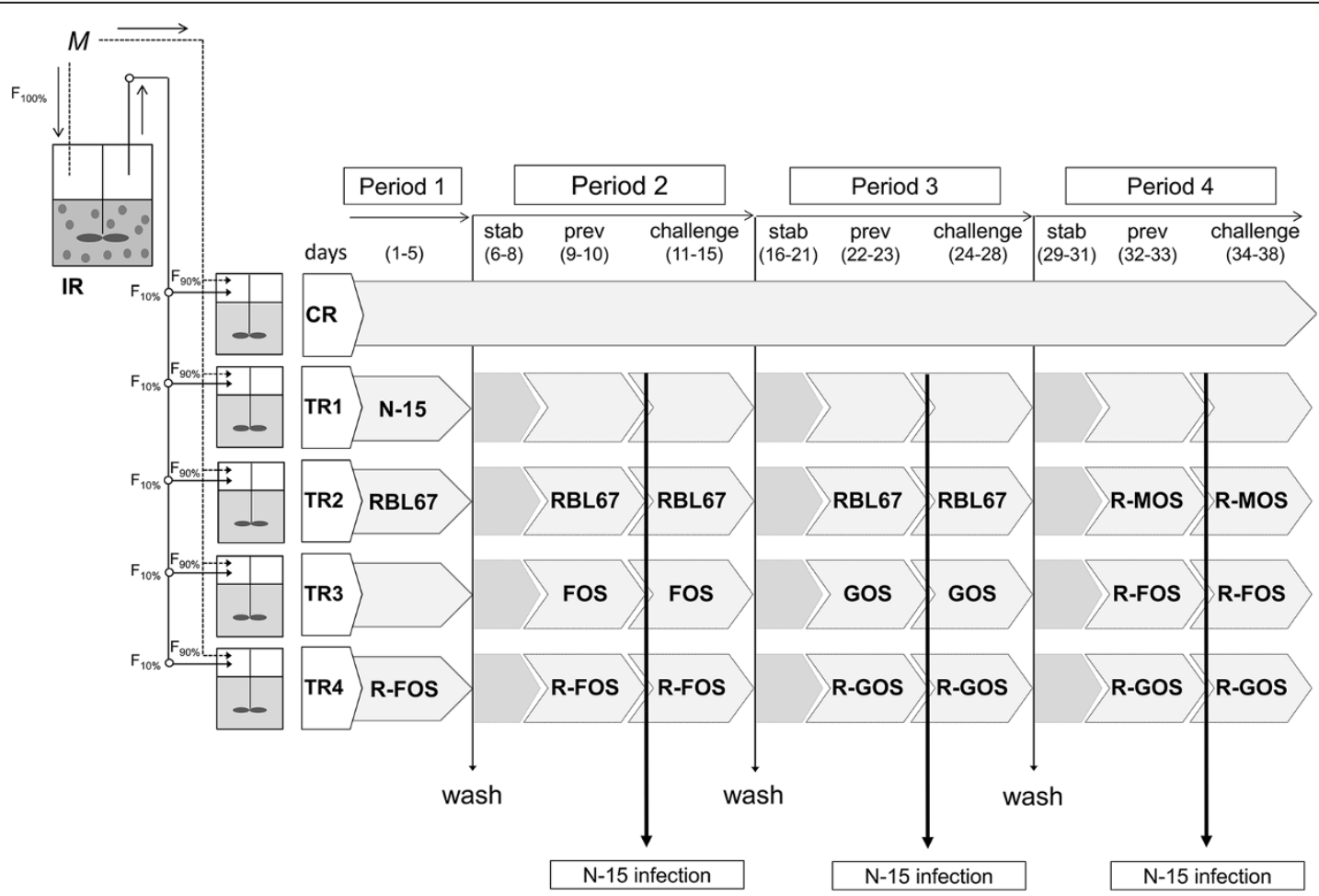

Figure 1 Experimental set-up of the continuous fermentation experiment. IR: inoculum reactor; CR: control reactor; TR: test reactors 1-4; F: flow rate; M: fresh medium inflow; stab: stabilization; prev: prevention; challenge: challenge with Salmonella N-15; N-15: S. Typhimurium N-15; RBL67: B. thermophilum RBL67; R-FOS/GOS/MOS: B. thermophilum RBL67 + respective prebiotic. 


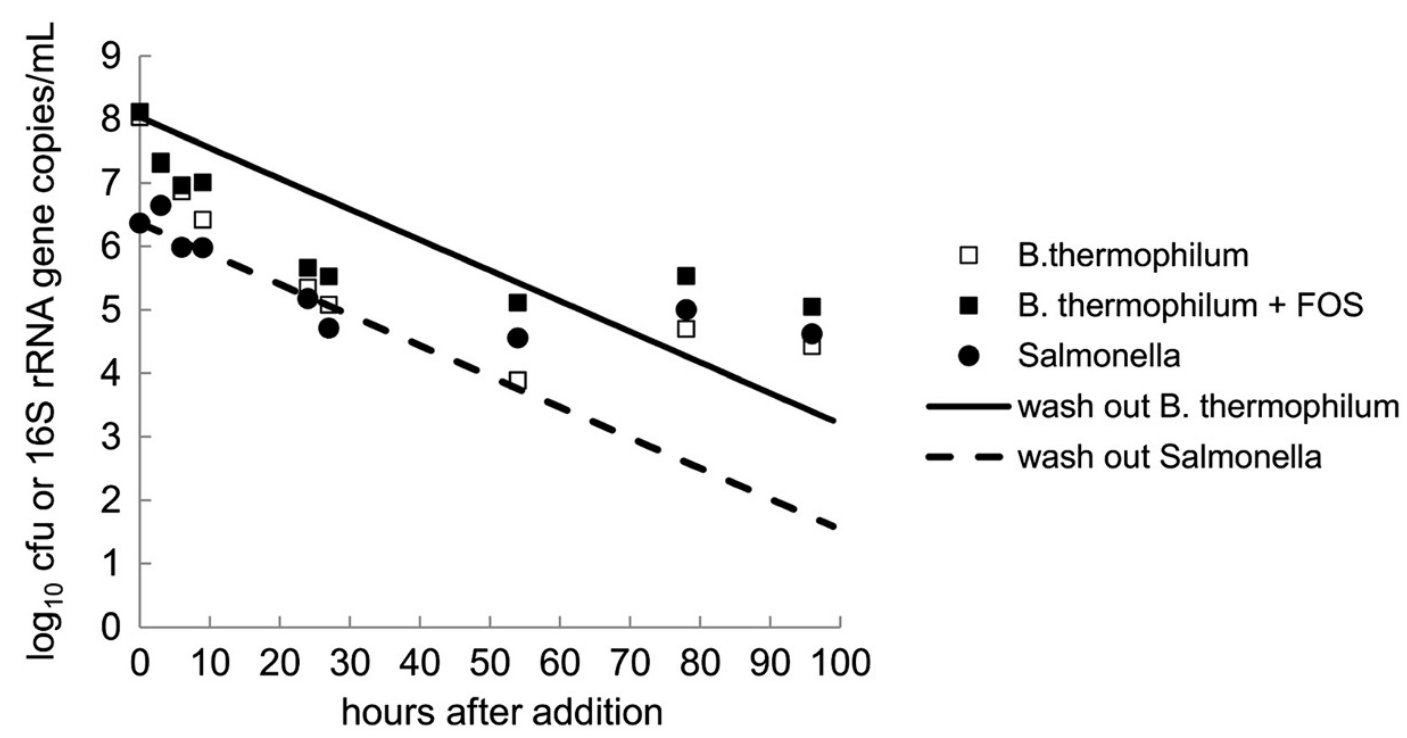

Figure 2 Salmonella and B. thermophilum in reactor effluents compared to theoretical washout curves during colonization tests. RBL67 was added once to TR2 and TR4 to reach $10^{8} \mathrm{CN} / \mathrm{mL}$, while TR4 was additionally supplied with $5.2 \mathrm{~g}$ of FOS/day. N-15 was added once to TR1 to reach $10^{6} \mathrm{cfu} / \mathrm{mL}$. Salmonella viable cell counts in reactor effluents was measured by plating on CHROMAgar ${ }^{\mathrm{TM}}$. B. thermophilum numbers were estimated by qPCR. Measured concentrations were compared to a theoretical washout curve.

Lactobacillus/Leuconostoc/Pediococcus and Bifidobacterium (Table 1). Total 16S rRNA, Clostridium Cluster IV and Bacteroides-Prevotella gene copy numbers remained stable independent of the tested conditions. Furthermore, the other bacterial groups, except for Bifidobacterium, did not show large changes (difference to $\mathrm{CR}<0.5 \log _{10} \mathrm{CN} /$ $\mathrm{mL}$ ) upon treatment application. Bifidobacterium numbers increased by more than $1 \log _{10} \mathrm{CN} / \mathrm{mL}$ during treatments with RBL67 alone and RBL67 combined with prebiotics (R-FOS, R-GOS, R-MOS). B. thermophilum was detected during daily treatments with RBL67, at concentrations ranging from 7.6 and $8.1 \log _{10} \mathrm{CN} / \mathrm{mL}$, but not in the other treatments and in CR (Table 1). The highest numbers of $B$. thermophilum were measured for RBL67 and FOS applied in combination (R-FOS). N-15 inoculation in absence of dietary treatments showed no effect on Enterobacteriaceae numbers, but was associated with a slight but significant increase of the group Lactobacillus/Leuconostoc/Pediococcus (0.6 $\log _{10} \mathrm{CN} / \mathrm{mL}$, period 2) and of Bifidobacterium (0.6 $\log _{10} \mathrm{CN} / \mathrm{mL}$, period 4) compared to CR.

Using 454 pyrosequencing of the entire 16S rRNA gene pool, a mean value of $6259 \pm 3730$ quality-filtered reads per sample was obtained with an average read length of $256 \pm$ $1 \mathrm{bp}$. All samples revealed the predominance of the 3 phyla, Firmicutes, Bacteroidetes and Proteobacteria (Additional file 1: Figure S1). Additionally, Actinobacteria were detected at low levels $(<1 \%$; except for R-FOS in period 2 with 1.9\%). Firmicutes and Bacteroidetes accounted for more than $80 \%$ of assigned reads in all samples for periods 2 and 3. However, during period 4, Proteobacteria

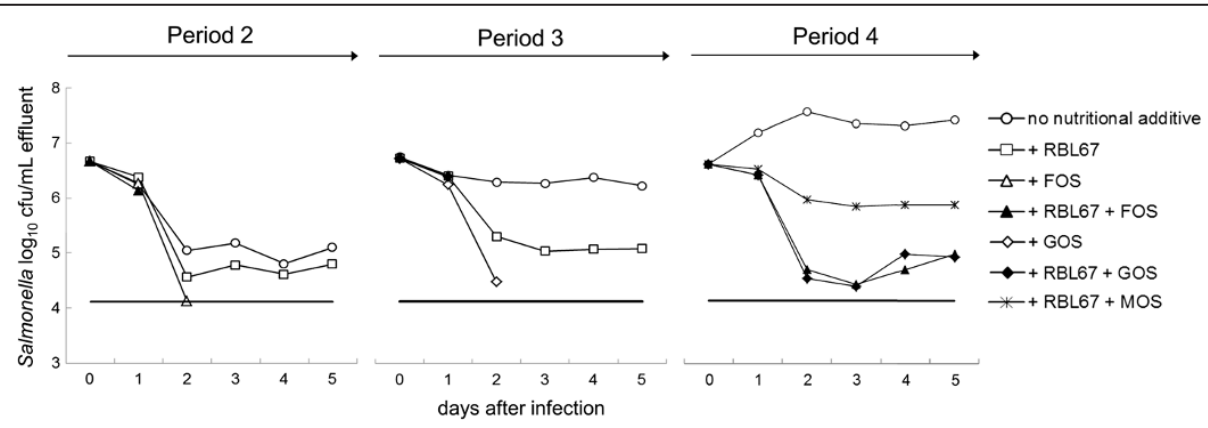

Figure 3 Salmonella cell counts determined in test reactors during treatment periods $\mathbf{2 - 4}$. Treatment periods $2-4$ were used to test the effect of prebiotics (FOS, GOS) or RBL67 or combinations of RBL67 with FOS, GOS or MOS on Salmonella N-15 colonization. RBL67 and/or prebiotics were added to TRs at $10^{8} \mathrm{CN} / \mathrm{mL}$ and $5.2 \mathrm{~g} /$ day, respectively during a 2 days prevention period and for 5 days after $\mathrm{N}-15$ challenge. $\mathrm{N}-15$ was inoculated once at $10^{6} \mathrm{cfu} / \mathrm{mL}$ and was monitored by plate counts on CHROMAgar ${ }^{\mathrm{Tm}}$ Salmonella. (-) Salmonella detection limit of $4.1 \mathrm{cfu} / \mathrm{mL}$. Cell counts at day 0 correspond to the inoculum added to the reactors. 
Table 1 16S rRNA gene copy numbers of bacterial groups by qPCR in reactors during periods 2-4

\begin{tabular}{|c|c|c|c|c|c|c|c|}
\hline \multirow[b]{2}{*}{ Treatment } & \multicolumn{7}{|c|}{ Bacterial group, $\log _{10}$ copies $/ \mathrm{mL}$ effluent } \\
\hline & $\begin{array}{l}\text { Bifidobacterium } \\
\text { thermophilum }\end{array}$ & $\begin{array}{l}\text { Bifidobacterium } \\
\text { spp. }\end{array}$ & $\begin{array}{l}\text { Bacteroides- } \\
\text { Prevotella }\end{array}$ & Enterobacteriaceae & $\begin{array}{l}\text { Lactobacillus/Leuconostoc/ } \\
\text { Pediococcus spp. }\end{array}$ & $\begin{array}{l}\text { Clostridium } \\
\text { Cluster IV }\end{array}$ & $\begin{array}{l}\text { total 16S } \\
\text { rRNA genes }\end{array}$ \\
\hline \multicolumn{8}{|l|}{ PERIOD 2} \\
\hline Control & n.d. & $6.4 \pm 0.2$ & $10.3 \pm 0.1$ & $9.6 \pm 0.1$ & $7.6 \pm 0.1$ & $10.0 \pm 0.1$ & $10.5 \pm 0.1$ \\
\hline $\mathrm{N}-15$ & n.d. & $6.5 \pm 0.2$ & $10.3 \pm 0.03$ & $9.6 \pm 0.1$ & $8.2 \pm 0.3^{*}$ & $10.1 \pm 0.1$ & $10.5 \pm 0.2$ \\
\hline RBL67 & $7.6 \pm 0.1$ & $8.3 \pm 0.2^{*}$ & $10.2 \pm 0.1$ & $10.0 \pm 0.1^{*}$ & $7.6 \pm 0.2$ & $10.0 \pm 0.1$ & $10.6 \pm 0.2$ \\
\hline FOS & n.d. & $6.0 \pm 0.2^{*}$ & $10.4 \pm 0.04$ & $9.9 \pm 0.2^{*}$ & $7.4 \pm 0.1$ & $10.0 \pm 0.03$ & $10.7 \pm 0.1$ \\
\hline R-FOS & $8.1 \pm 0.1$ & $8.7 \pm 0.2^{*}$ & $10.2 \pm 0.2$ & $9.9 \pm 0.2$ & $7.4 \pm 0.2^{*}$ & $10.0 \pm 0.1$ & $10.7 \pm 0.1$ \\
\hline \multicolumn{8}{|l|}{ PERIOD 3} \\
\hline Control & n.d. & $6.7 \pm 0.1$ & $10.0 \pm 0.03$ & $10.0 \pm 0.1$ & $8.2 \pm 0.3$ & $10.0 \pm 0.02$ & $10.6 \pm 0.1$ \\
\hline $\mathrm{N}-15$ & n.d. & $6.9 \pm 0.2$ & $10.1 \pm 0.2$ & $9.8 \pm 0.1^{*}$ & $8.2 \pm 0.2$ & $10.1 \pm 0.2$ & $10.6 \pm 0.2$ \\
\hline RBL67 & $7.7 \pm 0.1$ & $7.7 \pm 0.1^{*}$ & $10.1 \pm 0.2$ & $10.2 \pm 0.1^{*}$ & $8.6 \pm 0.2$ & $10.1 \pm 0.1$ & $10.6 \pm 0.2$ \\
\hline GOS & n.d. & $6.6 \pm 0.04$ & $9.9 \pm 0.2$ & $9.7 \pm 0.2^{*}$ & $8.1 \pm 0.2$ & $10.0 \pm 0.5$ & $10.5 \pm 0.1^{*}$ \\
\hline R-GOS & $7.7 \pm 0.1$ & $8.0 \pm 0.1^{*}$ & $10.0 \pm 0.2$ & $9.9 \pm 0.2$ & $8.3 \pm 0.3$ & $10.1 \pm 0.3$ & $10.5 \pm 0.2$ \\
\hline \multicolumn{8}{|l|}{ PERIOD 4} \\
\hline Control & n.d. & $6.4 \pm 0.1$ & $10.0 \pm 0.2$ & $10.0 \pm 0.2$ & $8.0 \pm 0.2$ & $9.5 \pm 0.02$ & $10.6 \pm 0.3$ \\
\hline $\mathrm{N}-15$ & n.d. & $7.0 \pm 0.1^{*}$ & $9.9 \pm 0.1$ & $9.8 \pm 0.1$ & $8.1 \pm 0.3$ & $9.8 \pm 0.1$ & $10.5 \pm 0.1$ \\
\hline R-MOS & $7.6 \pm 0.1$ & $8.1 \pm 0.1^{*}$ & $9.8 \pm 0.3$ & $9.8 \pm 0.2$ & $8.2 \pm 0.4$ & $9.5 \pm 0.3$ & $10.5 \pm 0.4$ \\
\hline R-FOS & $8.0 \pm 0.1$ & $8.4 \pm 0.1^{*}$ & $9.8 \pm 0.1$ & $9.9 \pm 0.2$ & $8.4 \pm 0.2^{*}$ & $9.7 \pm 0.1$ & $10.5 \pm 0.1$ \\
\hline R-GOS & $7.8 \pm 0.1$ & $8.3 \pm 0.03^{*}$ & $9.9 \pm 0.1$ & $10.0 \pm 0.2$ & $8.3 \pm 0.2$ & $9.8 \pm 0.2$ & $10.6 \pm 0.3$ \\
\hline
\end{tabular}

"Bacterial populations significantly different $(\mathrm{P}<0.05)$ from $\mathrm{CR}$ within a period; Values are given as means $\pm \mathrm{SD}$ (log ${ }_{10}$ copy numbers $/ \mathrm{mL}$ reactor effluent) calculated from three consecutive days (days 2-4) during N-15 challenge periods.

$\mathrm{N}-15$ : Salmonella N-15 without pro- or prebiotic; RBL67: B. thermophilum RBL67 alone; FOS: FOS alone; R-FOS: B. thermophilum RBL67 + FOS; GOS: GOS alone; R-GOS: B. thermophilum RBL67 + GOS; R-MOS: B. thermophilum RBL67 + MOS.

increased to up to $30 \%$ while Firmicutes and Bacteroidetes decreased to approximately $70 \%$ of all reads. The phylum Proteobacteria displayed a steady increase in all reactors during the fermentation, including in $\mathrm{CR}$ where no treatment was applied. In general, pro- and prebiotic treatments and N-15 infection did not markedly impact microbiota composition. At the phylum level, Bacteroidetes increased and Firmicutes decreased in the N-15 (alone) and RBL67 treatments compared to $\mathrm{CR}$ (period 3). On the family level a consistent increase of Erysipelotrichaceae was observed with prebiotics, alone (FOS, GOS) or in combination with RBL67 (R-FOS, R-FOS, R-MOS), compared to CR, with highest effect for R-FOS (6.4\% compared to $0.3 \%$ in CR, period 2 and $4.7 \%$ compared to $0.1 \%$ in CR, period 4 ) (Figure 4). Changes observed at the genus level (Additional file 2: Figure S2) were consistent with observations at the family level. The genus Sharpea, a member of the family Erysipelotrichaceae, was highly abundant in the TRs after FOS or GOS treatments and the combined treatments of RBL67 with prebiotics (R-FOS, R-GOS, R-MOS) compared to $\mathrm{CR}$. The genus increased to $6 \%$ (period 2) and $5 \%$ (period 4) of total reads after the R-FOS treatment with values $<0.1 \%$ in $C R$.
Effect of prebiotics, RBL67 and N-15 infection on gut microbiota metabolism

Metabolite concentrations were measured by HPLC and mean values of three consecutive days (days 2-4), corresponding to pseudo-steady states of the N-15 challenge periods, were compared to corresponding data from the CR (Table 2).

In the CR, the total short chain fatty acid (SCFA) concentration was stable from periods 1 to $3(162 \pm 1 \mathrm{mM})$, but a slight decrease to $153 \pm 1 \mathrm{mM}$ was observed during period 4, corresponding to a switch of the metabolite molar ratio (acetate:propionate:butyrate) from 57:29:14 (period 1-3) to 51:34:15 (period 4). The total SCFA concentration in the TRs was increased by $29 \pm 4 \%$ compared to the CR for treatments with FOS and GOS alone and combined with RBL67. Acetate $(+38 \pm 10 \%)$ and propionate $(+28 \pm 4 \%)$ levels were most increased with FOS, GOS, R-FOS and R-GOS, whereas R-FOS also induced a significant increase of butyrate $(18 \%, 45 \%$ and $7 \%$ for period 1,2 and 4, respectively) compared to the CR. The total SCFA concentration was also significantly increased in TRs treated with RBL67 alone $(+5 \pm 1 \%$, periods $2-3)$ or with R-MOS (+11\%), although to a lesser extent than for the 


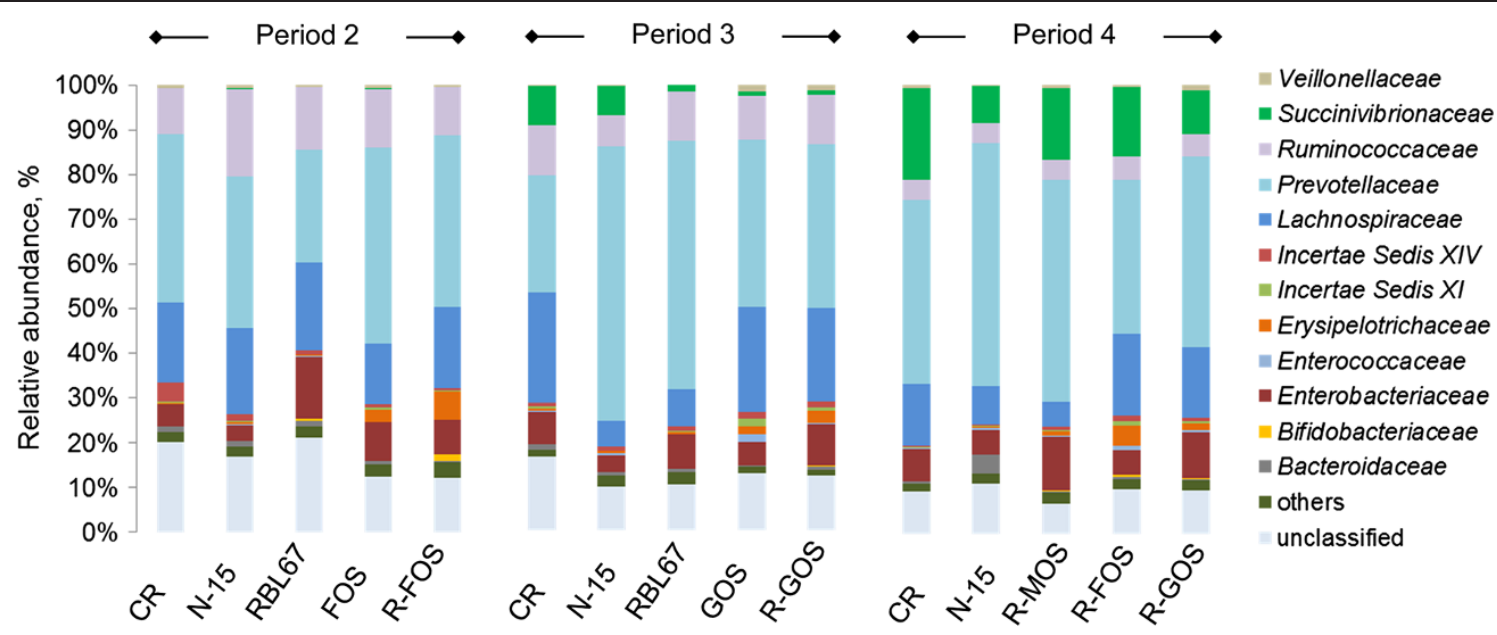

Figure 4 Microbial composition in reactors during treatment periods 2-4 measured by $\mathbf{4 5 4}$ pyrosequencing on family level. The microbiota profile in reactor effluents during treatment periods was analyzed by 454 pyrosequencing of the entire $16 \mathrm{~S}$ rRNA gene pool in the V5-V6 region. Reactor effluents were pooled in a ratio 1:1 from two consecutive days of the N-15 challenge period (days 3 and 4) for genomic DNA extraction and subsequent sequencing on a 454 Life Sciences Genome Sequencer GS FLX instrument. Quality-filtered sequencing reads were assigned using the Ribosomal Database Project (RDP) Bayesian classifier (v2.1) and applying a confidence threshold of $80 \%$. CR: control reactor; values $<1 \%$ are summarized in the group others.

other prebiotics. Treatment with RBL67 increased acetate $(+12 \pm 2 \%$, periods $1-2)$ and butyrate concentrations $(+16 \pm 2 \%$, periods $1-2)$, while R-MOS mainly stimulated propionate production $(+25 \%)$. Infection with $\mathrm{N}-15$ (alone) had little effect on metabolite productions, except for an increase in acetate concentration $(+11 \pm 2 \%$, periods 1 and 4). Branched chain fatty acids (BCFA) were measured at low amounts $(<7 \mathrm{mM})$ in all reactors. Formate and lactate were not detected throughout the fermentation (data not shown).

\section{Discussion}

We recently described and validated a novel in vitro continuous fermentation model (PolyFermS) simulating conditions of the swine proximal colon. The model consists of parallel reactors inoculated with the same microbiota [33]. In this study, we report the first time application of this swine PolyFermS model to investigate the effects of a probiotic strain, B. thermophilum RBL67, prebiotics (FOS, GOS, MOS) and combinations thereof, on $S$. Typhimurium $\mathrm{N}-15$ colonization in the presence of a diverse gut microbiota.

In a first test, RBL67 and N-15 were shown to colonize the system after one single inoculation. They reached stable and similar numbers after 1 to 2 days. Our in vitro model data suggest competitive and adaptive traits of RBL67 and $\mathrm{N}-15$ in co-culture with the modeled porcine microbiota. These results are in agreement with previous studies done with one- and three-stage chemostat models of the child colon $[27,34]$. The increasing capacity of N-15 to colonize the model observed from periods 2 to 4 , underlines the robustness and/or adaptation of Salmonella in simulated colonic conditions of the swine colon. This suggests that the PolyFermS model is suitable to mimic a Salmonella carrier state of pigs with continuous shedding of Salmonella [35]. Moreover, an incomplete removal of N-15 during washing periods of reactors may partly explain the enhanced competition of $\mathrm{N}-15$ over time, because viable cells of Salmonella were detected in the effluents by plating after careful washing with $10 \%$ chlorine for $1 \mathrm{~h}$ and prior to $\mathrm{N}-15$ challenge in periods 3 and 4 (data not shown). This persistence of Salmonella could be due to the formation of biofilms in the reactor, which is known to increase sterilization resistance [36]. This effect may be avoided in the future by replacing the test reactors with sterile units before each new treatment period. We also reported an increase of the family Succinivibrionaceae during the course of the fermentation for the first-stage immobilized cell and all second-stage reactors for the same fermentation test [33]. Salmonella and Succinivibrionaceae belong to the $\gamma$-subclass of the phylum Proteobacteria [37]. Increased numbers of Succinivibrionaceae correlated with the increased capacity of N-15 to grow in the system, suggesting that this group potentially supported $\mathrm{N}-15$ persistence and growth in periods 3 and 4 after washing. Such co-occurrence of related bacteria has been previously reported for Salmonella invasion in a mouse infection model in the presence of high titers of E. coli [38].

Colonization of $\mathrm{N}-15$ in the porcine PolyFermS was strongly inhibited by the addition of FOS or GOS. This 
Table 2 Concentration (mM) and molar ratios (\%) of metabolites measured by HPLC during periods 1-4

\begin{tabular}{|c|c|c|c|c|c|}
\hline & Acetate & Propionate & Butyrate & total SCFA & ratio (acetate:propionate:butyrate) \\
\hline \multicolumn{6}{|l|}{ PERIOD 1} \\
\hline Control & $94.6 \pm 2.3$ & $45.8 \pm 1.3$ & $22.5 \pm 0.4$ & $162.9 \pm 1.8$ & $58: 28: 14$ \\
\hline $\mathrm{N}-15$ & $104.2 \pm 1.0^{*}$ & $43.6 \pm 1.5$ & $22.9 \pm 1.1$ & $170.6 \pm 3.0^{*}$ & $61: 26: 13$ \\
\hline RBL67 & $96.8 \pm 6.1$ & $43.0 \pm 0.3^{*}$ & $25.7 \pm 1.0^{*}$ & $165.5 \pm 5.4$ & $58: 26: 16$ \\
\hline R-FOS & $146.8 \pm 5.9^{*}$ & $52.1 \pm 3.3^{*}$ & $26.4 \pm 0.9^{*}$ & $225.3 \pm 1.8^{*}$ & $65: 23: 12$ \\
\hline \multicolumn{6}{|l|}{ PERIOD 2} \\
\hline Control & $92.4 \pm 3.7$ & $48.0 \pm 2.0$ & $20.7 \pm 0.8$ & $161.0 \pm 5.1$ & $57: 30: 13$ \\
\hline $\mathrm{N}-15$ & $94.0 \pm 6.9$ & $45.2 \pm 1.1$ & $21.9 \pm 1.8$ & $161.1 \pm 8.2$ & $58: 28: 14$ \\
\hline RBL67 & $102.3 \pm 2.6^{*}$ & $44.3 \pm 1.3^{*}$ & $24.3 \pm 1.3^{*}$ & $170.9 \pm 5.0^{*}$ & $60: 26: 14$ \\
\hline FOS & $126.4 \pm 5.2^{*}$ & $58.4 \pm 1.1^{*}$ & $21.0 \pm 2.4$ & $205.8 \pm 6.0^{*}$ & $61: 28: 10$ \\
\hline R-FOS & $112.2 \pm 1.0^{*}$ & $60.6 \pm 0.9^{*}$ & $29.9 \pm 1.1^{*}$ & $202.7 \pm 1.5^{*}$ & 55:30:15 \\
\hline \multicolumn{6}{|l|}{ PERIOD 3} \\
\hline CR & $89.5 \pm 1.8$ & $46.9 \pm 0.1$ & $27.0 \pm 1.8$ & $163.4 \pm 3.6$ & 55:29:16 \\
\hline SAL & $86.1 \pm 1.4^{*}$ & $50.0 \pm 2.8$ & $22.9 \pm 5.2^{*}$ & $159.0 \pm 5.2$ & $54: 31: 14$ \\
\hline RBL67 & $101.3 \pm 3.1^{*}$ & $47.3 \pm 2.0$ & $22.7 \pm 5.9^{*}$ & $171.3 \pm 5.9$ & $59: 28: 13$ \\
\hline GOS & $122.7 \pm 4.8^{*}$ & $61.1 \pm 5.5^{*}$ & $21.6 \pm 5.0^{*}$ & $205.4 \pm 5.0^{*}$ & 60:30:10 \\
\hline R-GOS & $117.6 \pm 2.0^{*}$ & $60.4 \pm 2.7^{*}$ & $27.1 \pm 5.9$ & $205.1 \pm 6.0^{*}$ & $57: 29: 13$ \\
\hline \multicolumn{6}{|l|}{ PERIOD 4} \\
\hline CR & $78.7 \pm 0.8$ & $51.4 \pm 1.0$ & $23.2 \pm 0.4$ & $153.3 \pm 1.4$ & 51:34:15 \\
\hline SAL & $90.1 \pm 1.0^{*}$ & $50.9 \pm 0.9$ & $22.8 \pm 1.7$ & $163.8 \pm 1.7^{*}$ & $55: 31: 14$ \\
\hline R-MOS & $82.7 \pm 3.2^{*}$ & $64.1 \pm 1.5^{*}$ & $22.8 \pm 2.9$ & $169.3 \pm 1.0^{*}$ & 49:38:13 \\
\hline R-FOS & $114.6 \pm 7.6^{*}$ & $65.0 \pm 1.3^{*}$ & $24.7 \pm 0.6^{*}$ & $204.3 \pm 6.0^{*}$ & $56: 32: 12$ \\
\hline R-GOS & $118.5 \pm 1.1^{*}$ & $68.2 \pm 3.0^{*}$ & $20.1 \pm 0.3^{*}$ & $206.8 \pm 2.9^{*}$ & $57: 33: 10$ \\
\hline
\end{tabular}

*Means significantly different $(P<0.05)$ from $C R$ within a metabolite and period using the Kruskal-Wallis pairwise comparison.

Reported are mean values (days $2-4$ of $\mathrm{N}-15$ challenge periods) $\pm \mathrm{SD}$ and ratios are given as percentage of total SCFA (acetate, propionate, butyrate).

$\mathrm{N}-15$ : S. Typhimurium N-15 without pro- or prebiotic; RBL67: B. thermophilum RBL67 alone; FOS: FOS alone; R-FOS: $B$. thermophilum RBL67 + FOS; GOS: GOS alone; R-GOS: B. thermophilum RBL67 + GOS; R-MOS: B. thermophilum RBL67 + MOS.

correlated with an increase of SCFA production, especially acetate and propionate. A $5 \mathrm{mM}$ undissociated acetic acid solution was reported to inhibit Salmonella growth [39-41]. In our study, concentrations of undissociated acetic acids were calculated to be $>6 \mathrm{mM}(\mathrm{pH}=6.0)$ for treatments with FOS and GOS, compared to levels $\leq 5 \mathrm{mM}$ in the reactor spiked with N-15 alone. RBL67 combined with FOS or GOS showed an enhanced inhibition of N-15 compared to single treatments with pro- or prebiotics. We chose strain RBL67, because it produces BLIS (thermophilicin B67), which exhibits an antagonistic effect against Salmonella and Listeria [24-26]. The production of acetate was decreased for R-FOS and R-GOS compared to prebiotics alone (Table 2). This suggests that BLIS contributed to $\mathrm{N}-15$ inhibition in combination with organic acids produced by FOS and GOS. The lower dosage of the prebiotic in R-MOS compared to the other combinations and the stimulation of propionate rather than acetate production, may explain the less pronounced effect on $\mathrm{N}-15$ colonization. However, MOS has previously been shown to block enteropathogen adhesion to the mannose- rich surface glycoproteins of epithelial villi via binding of its $\alpha$-D-Mannan to Type 1 fimbriae of enteropathogens and thus may reduce the risk of infection by this mechanism [42].

The antagonistic effect of RBL67 was less pronounced in this study compared to a previous report [27]. A strong inhibition of Salmonella and a rapid metabolic rebalancing of the gut microbiota after antibiotic treatments were observed when RBL67 was added before or after infection in an in vitro intestinal fermentation model inoculated with child microbiota [27]. In contrast, Zihler et al. [30] did not detect an anti-Salmonella effect of RBL67. This may be explained by different host microbiota, model set-up and probiotic:pathogen ratios used for all these studies, i.e. 16:1 (this study), 3050:1 [27] and 2:1 [30].

FOS has been reported to stimulate butyrate production in some studies with piglets $[16,43]$. In our study, we observed an increased butyrate production with the combination of FOS and RBL67. Because bifidobacteria do not produce butyrate [44], we presume that FOS was first degraded e.g. by RBL67, followed by cross-feeding reactions 
with butyrate-producing bacteria (e.g. Roseburia spp. or Megasphaera; [45]). Interestingly, while butyrate has been linked to a series of health-related properties (reviewed by Russell et al. [13]), it was also shown to repress invasion gene expression of Salmonella [14].

The microbiota composition from CR to TR effluents only changed marginally after RBL67 and prebiotic treatments. In particular, we did not observe a growth stimulation of bifidobacteria or lactobacilli in the FOS and GOS treatments, as it was previously shown in vitro with human gut microbiota treated with FOS and inulin [30,46] or pig microbiota treated with GOS [15,47]. Divergent results have been reported concerning the effect of FOS and GOS in vivo. Patterson et al. [12] reported increased numbers of bifidobacteria and lactobacilli in young pigs fed with inulin. In contrast, Mountzouris et al. [17] and Mikkelsen and Jensen [16] did not observe a significant stimulation of bifidobacteria and lactobacilli in pigs fed with FOS and transgalactooligosaccharides. These discrepancies may be explained by different prebiotic structures, dosage and methodology $[4,48]$, complicating a direct comparison between the studies. Furthermore, other bacteria of the gut microbiota, including Salmonella and members of Roseburia and Bacteroides, can efficiently utilize FOS and GOS as growth substrates [49-51] and can directly compete for these nutrients with bifidobacteria and lactobacilli.

Using 454 pyrosequencing, we detected a consistent increase in the relative abundance of the genus Sharpea upon addition of prebiotics. This suggests that Sharpea spp. play a role for prebiotic degradation. They belong to the family Erysipelotrichaceae within the Clostridium Cluster XVII. Members of this genus are heterofermentative and produce lactic acid and $\mathrm{CO}_{2}$ from glucose. They were first isolated from horse feces and are closely related to Eggerthia catenaformis [52,53]. Higher net substrate availability upon prebiotic addition may be responsible for a higher abundance of Sharpea spp. Erysipelotrichaceae were also more abundant in pigs with increased feed consumption $[54,55]$, and accounted for a sevenfold higher proportion in mice fed a high energy diet [56]. Yet, the exact role of the genus Sharpea remains unclear and further insights into prebiotic degradation or its involvement in possible cross-feeding reactions should be elucidated in future research.

\section{Conclusion}

Our data highlight the suitability of the novel porcine PolyFermS model to discover ecophysiological changes resulting from different nutritional treatments on $S$. Typhimurium N-15 colonization. We showed that FOS and GOS distinctively inhibit N-15 colonization in this model, while the effect was enhanced in presence of $B$. thermophilum RBL67. This was likely due to a combined effect of SCFA and antimicrobial compound production and competition. We showed that RBL67 stimulates butyrate production in the presence of FOS, beneficially impacting swine gut health. Future research should thus focus on elucidating the antagonistic mechanisms of RBL67 towards $\mathrm{N}-15$ in the presence of prebiotics such as FOS and GOS.

\section{Methods}

\section{Bacterial strains}

B. thermophilum RBL67 (LMG S-23614, Laboratory of Food Biotechnology, ETH Zurich) was isolated from human baby feces [26]. $S$. Typhimurium N-15 was obtained from a clinical case and was supplied by the National Center for Enteropathogenic Bacteria and Listeria (NENT; University of Zurich, Zurich, Switzerland). RBL67 and $\mathrm{N}-15$ were cultured from a glycerol stock $\left(33 \%,-80^{\circ} \mathrm{C}\right)$ in serum flasks containing the fermentation medium used to simulate swine chyme [33], at $37^{\circ} \mathrm{C}$ for $15 \mathrm{~h}$. The headspace of the serum flasks was flushed with an $\mathrm{N}_{2}: \mathrm{CO}_{2}$ (3:1) gas mixture before autoclaving to generate anaerobic conditions. Viable cell counts of Salmonella were determined by plating serial 10 -fold dilutions in duplicate on CHROMAgar ${ }^{\text {Tix }}$ Salmonella (Becton Dickinson AG, Allschwil, Switzerland).

\section{Prebiotics}

Fibrulose F97 (FOS) (Cosucra Groupe Warcoing S. A., Warcoing, Belgium) contains oligofructose $(\geq 97 \%$ [wt/wt]) and minor amounts of free fructose, glucose and sucrose $(\leq 5 \%[\mathrm{wt} / \mathrm{wt}])$, and has a polymerization degree of $94 \% \leq 20$. Vivinal GOS 90 (GOS), composed of $96.5 \%$ GOS, $2 \%$ lactose, $0.7 \%$ glucose and $0.8 \%$ galactose, was supplied by Friesland Campina Domo (Amersfoort, Netherlands). BioMos (MOS) was obtained from Alltech (Sarney, Ireland).

\section{Fermentation set-up}

The experimental set-up of the continuous in vitro fermentation model was presented in detail by Tanner et al. [33]. Briefly, the fermentation model consisted of a twostage reactor set-up, with six reactors operated under conditions of the swine proximal colon $\left(38^{\circ} \mathrm{C}, \mathrm{pH} 6.0\right.$, retention time $9 \mathrm{~h}$, anaerobiosis by $\mathrm{CO}_{2}$ headspace flushing) (Figure 1). The inoculum reactor (IR) containing 30\% (v/v) polysaccharide gel beads immobilizing swine fecal microbiota was used to continuously inoculate five subsequent reactors (one control (CR) and four test reactors (TR1-4)) with $10 \%$ effluent. CR and TR1-4 were additionally fed with 90\% fresh nutritive medium, designed to simulate swine chyme [33]. While IR and CR were operated under constant conditions during the entire fermentation period, the test reactors (TR1-4) were used to test N-15 and RBL67 colonization (period 1) and effects of RBL67 and/or prebiotics on N-15 colonization (periods 2-4) (Figure 1). Between each period, test reactors were disconnected from the IR, washed with $10 \%$ chlorine solution, reconnected and 
microbiota composition and activity was re-established for minimum 3 days before application of a new treatment [33].

\section{Period 1: RBL67- N-15 colonization}

Colonization of $S$. Typhimurium N-15 and B. thermophilum RBL67 was tested during period 1 (Figure 1). N-15 was inoculated in TR1 once to reach a cell concentration of $10^{6} \mathrm{cfu} / \mathrm{mL}$ reactor. RBL67 was added once to TR2 and TR4 for a final gene copy number of $10^{8} \mathrm{CN} / \mathrm{mL}$, while TR4 was additionally supplied with $5.2 \mathrm{~g}$ of FOS/day. Effluent samples were analyzed after 3, 6, 9, 24, 27, 54, 78 and $96 \mathrm{~h}$ for enumeration of Salmonella and B. thermophilum with plate counts and qPCR, respectively. Measured concentrations of N-15 and RBL67 were compared to a theoretical washout curve, calculated with the formula: $c_{t}=c_{0}{ }^{*} e^{(-t / R T)}$, where RT is the mean retention time $(9 \mathrm{~h}), \mathrm{c}_{0}$ and $\mathrm{c}_{\mathrm{t}}$ are cell concentrations of bacteria at time point 0 and $t$, respectively.

\section{Periods 2-4: $\mathrm{N}-15$ treatment periods}

The effects of RBL67, FOS, GOS and combinations of RBL67 with FOS (R-FOS), GOS (R-GOS) and MOS (R-MOS) on $\mathrm{N}-15$ colonization were tested during periods 2-4. For each period one reactor served as control (CR) and one reactor was infected with N-15 only (Figure 1). Treatment periods were divided into three phases: stabilization (stab) was carried out for 3 days (periods 2 and 4) or 5 days (period 3), prevention (prev) with pro- and/or prebiotics was done for 2 days, and challenge with N-15 was tested for 5 days, while addition of RBL67 and/or prebiotics was pursued. During prevention and challenge periods RBL67 and prebiotics were applied daily (Figure 1). All test reactors were infected once with N-15 on the first day of the challenge period.

RBL67 and N-15 inoculum was prepared from an overnight culture, which was centrifuged $(6000 \times \mathrm{g}, 5 \mathrm{~min})$ and resuspended in fresh fermentation medium. Reactors were inoculated with a syringe to obtain final concentrations of approximately $10^{8} \mathrm{CN} / \mathrm{mL}$ for RBL67 and $10^{6} \mathrm{cfu} / \mathrm{mL}$ for $\mathrm{N}-15$ corresponding to a probiotic: pathogen ratio of approximately 100:1. FOS and GOS were supplied twice daily for a total of $5.2 \mathrm{~g} /$ day. This addition level was selected to correspond to approximately $3 \%(\mathrm{w} / \mathrm{w})$ of the daily feed for pigs, considering a $2 \mathrm{~kg} / \mathrm{d}$ feed intake and a scale factor of 0.09 for the ratio of the reactor volume $(260 \mathrm{~mL})$ to the pig proximal colon volume in vivo (approx. 2.9 L [57]). MOS was supplied only once per day and at $1.5 \%(\mathrm{w} / \mathrm{w}, 2.6 \mathrm{~g} /$ day), because higher amounts led to blocking of the flow. Reactor effluent samples were collected daily during the entire fermentation and analyzed for bacterial composition and activity.

\section{qPCR analyses}

Predominant bacterial groups of the swine gut microbiota [58] in reactor effluents were enumerated by qPCR.
Genomic DNA was extracted using the FastDNA Spin Kit for soil (MP Biomedicals, Illkirch, France) according to the manufacturer's instructions. qPCR targets were: total bacteria (total $16 \mathrm{~S}$ rRNA gene copies), Bacteroides-Prevotella group, Enterobacteriaceae, Lactobacillus/Pediococcus/ Leuconostoc spp., Clostridium Cluster IV and Bifidobacterium spp. (Additional file 3: Table S1). Standard curve preparation and reaction conditions were carried out as described by Dostal et al. [59] using a reaction volume of $25 \mu \mathrm{l}$ and an ABI PRISM 7500-PCR sequence detection system (Applied Biosystems, Zug, Switzerland). All assays were carried out using the $2 \times$ SYBR Green PCR Master Mix (Applied Biosystems).

B. thermophilum enumeration was performed using primers bthermRTF and bthermRTR and the Taqman probe bthermTqm (Additional file 3: Table S1) [60]. The RT-QP2X-03WOULR Mastermix (Eurogentec s.a., Seraing, Belgium) was used and standard curve preparation and reaction conditions were carried out as described previously $[59,60]$.

\section{Pyrosequencing}

Effluent samples of CR and TRs from periods 2-4 were analyzed using 454 pyrosequencing on the V5-V6 region of the entire 16S rRNA gene pool. Reactor effluents from two consecutive days during the $\mathrm{N}-15$ challenge (day 3 and 4) were pooled in a ratio 1:1, prior to DNA extraction using the FastDNA SPIN Kit for soil (MP Biomedicals). Genomic DNA extracts were sequenced by DNAVision SA (Charleroi, Belgium) on a 454 Life Sciences Genome Sequencer GS FLX instrument (Roche AG, Basel, Switzerland), and subsequent taxonomic assignment of the 16S rRNA gene reads was done as described previously [61]. Quality-filtered sequencing reads were assigned using the Ribosomal Database Project (RDP) Bayesian classifier (v 2.1) [62] and applying a confidence threshold of $80 \%$. The entire 454 pyrosequencing dataset has been deposited to the National Center for Biotechnology (NCBI) Sequence Read Archive under accession number SRP044728.

\section{Metabolite analysis}

Reactor effluents were analyzed for SCFAs (acetate, propionate and butyrate), BCFAs (valerate, iso-valerate and iso-butyrate), formate and lactate by HPLC (Thermo Fisher Scientific Inc. Accela, Wohlen, Switzerland) [33]. Effluent samples were centrifuged $\left(14000 \times \mathrm{g}, 10 \mathrm{~min}, 4^{\circ} \mathrm{C}\right)$; the resulting supernatant was diluted 1:10 with ultrapure water and directly filtered through a $0.45 \mu \mathrm{m}$ nylon filter (Infochroma AG, Zug, Switzerland). The analysis was carried out using an Aminex HPX-87H column (Bio-Rad Laboratories AG, Reinach, Switzerland) and $10 \mathrm{mM} \mathrm{H}_{2} \mathrm{SO}_{4}$ as eluent. Mean metabolite concentrations $(\mathrm{mM})$ were estimated from duplicate analyses. Total SCFA contents correspond to the sum of acetate, propionate and butyrate. 


\section{Statistical analysis}

All statistical analyses were performed using JMP 10.0 (SAS Institute Inc., Cary, NC). Prior to statistical analysis qPCR data were $\log _{10}$ transformed. HPLC and qPCR data are expressed as means \pm SD from three consecutive days (days 2-4) during N-15 challenge periods. Metabolite and qPCR data from each treatment reactor were compared pairwise to the control reactor within the same period using the non-parametric Kruskal-Wallis Test. P-values $<0.05$ were considered significant.

\section{Additional files}

\begin{abstract}
Additional file 1: Figure S1. Microbial composition in reactors during treatment periods 2-4 measured by 454 pyrosequencing on phylum level. Microbial composition in reactor effluents was analyzed by 454 pyrosequencing of the entire $16 \mathrm{~S}$ rRNA gene pool in the V5-V6 region. Reactor effluents were pooled in a ratio 1:1 from two consecutive days of the N-15 challenge period (days 3 and 4) for genomic DNA extraction and subsequent sequencing on a 454 Life Sciences Genome Sequencer GS FLX instrument. Quality-filtered sequencing reads were assigned using the Ribosomal Database Project (RDP) Bayesian classifier (v2.1) and applying a confidence threshold of $80 \%$. CR: control reactor; values $<1 \%$ are summarized in the group others.
\end{abstract}

Additional file 2: Figure S2. Microbial composition in reactors during treatment periods 2-4 measured by 454 pyrosequencing on genus level. Microbial composition in reactor effluents was analyzed by 454 pyrosequencing of the entire 16S rRNA gene pool in the V5-V6 region. Reactor effluents were pooled in a ratio 1:1 from two consecutive days of the $\mathrm{N}-15$ challenge period (days 3 and 4) for genomic DNA extraction and subsequent sequencing on a 454 Life Sciences Genome Sequencer GS FLX instrument. Quality-filtered sequencing reads were assigned using the Ribosomal Database Project (RDP) Bayesian classifier (v2.1) and applying a confidence threshold of $80 \%$. CR: control reactor; values $<1 \%$ are summarized in the group others.

Additional file 3: Table S1. Primers and probes used for detection of bacterial target groups with qPCR.

\section{Abbreviations}

RBL67: Bifidobacterium thermophilum RBL67; N-15: Salmonella enterica subsp. enterica serovar Typhimurium N-15; FOS: Fructooligosaccharide; GOS: Galactooligosaccharide; MOS: Mannanoligosaccharide; IR: Inoculum reactor; CR: Control reactor; TR: Test reactor; CN: Gene copy numbers; R-FOS: RBL67 + FOS; R-GOS: RBL67 + GOS; R-MOS: RBL67 + MOS; SCFA: Short chain fatty acids; BCFA: Branched chain fatty acids; qPCR: Quantitative PCR; BLIS: Bacteriocin-like inhibitory substance.

\section{Competing interests}

The authors declare that they have no competing interests.

\section{Authors' contributions}

SAT designed and performed experiments, carried out data analysis and wrote the manuscript. CC and $C L$ participated in the design of the experiments, analysis and interpretation of data and writing of the manuscript. AZB designed experiments and analyzed the data. All authors read and approved the final manuscript.

\section{Acknowledgements}

This work was supported by the Commission for Technology and Innovation (project number: 11962.1). We thank the Genetic Diversity Center (GDC) at ETH Zurich for support for quantitative real time PCR analysis and Dr. Franck Grattepanche, Eugenia Rigozzi, Eun-Hee Doo, Lukas Meile and Simon Galenda for technical assistance. We further thank Dr. Fabienne Wichmann for proof reading of the manuscript.
Received: 11 August 2014 Accepted: 6 October 2014

Published online: 24 October 2014

\section{References}

1. European Food Safety Authority (EFSA): Analysis of the baseline survey on the prevalence of Salmonella in holdings with breeding pigs in the EU, 2008. EFSA J 2009, 7:1377-1470.

2. Scott KP, Gratz SW, Sheridan PO, Flint HJ, Duncan SH: The influence of diet on the gut microbiota. Pharmacol Res 2013, 69:52-60.

3. Pieper R, Bindelle J, Rossnagel B, Van Kessel A, Leterme P: Effect of carbohydrate composition in barley and oat cultivars on microbial ecophysiology and proliferation of Salmonella enterica in an in vitro model of the porcine gastrointestinal tract. Appl Environ Microbiol 2009, 75:7006-7016.

4. Allen HK, Levine UY, Looft T, Bandrick M, Casey TA: Treatment, promotion, commotion: antibiotic alternatives in food-producing animals. Trends Microbiol 2013, 21:114-119.

5. FAO/WHO: Joint FAO/WHO Working Group Report on Drafting Guidelines for the Evaluation of Probiotics in Food. ; 2002.

6. Callaway TR, Edrington TS, Anderson RC, Aiello CW, Byrd JA II, Kogut MH, Harvey RB, Nisbet DJ: Using Antimicrobial Cultures, Bacteriocins, and Bacteriophages to Reduce Carriage of Foodborne Pathogens in Cattle and Swine. In Protective Cultures, Antimicrobial Metabolites and Bacteriophages for Food and Beverage Biopreservation. Edited by Lacroix C. Cambridge, UK: Woodhead Publishing Ltd; 2011:204-224.

7. Casey PG, Gardiner GE, Casey G, Bradshaw B, Lawlor PG, Lynch PB, Leonard FC, Stanton C, Ross RP, Fitzgerald GF, Hill C: A five-strain probiotic combination reduces pathogen shedding and alleviates disease signs in pigs challenged with Salmonella enterica serovar Typhimurium. Appl Environ Microbio/ 2007, 73:1858-1863.

8. Chang CH, Chen YS, Chiou MT, Su CH, Chen DS, Tsai CE, Yu B, Hsu YM: Application of Scutellariae radix, Gardeniae fructus, and probiotics to prevent Salmonella enterica Serovar Choleraesuis infection in swine. Evid Based Complement Alternat Med 2013, 2013:8.

9. Zhang L, Xu YQ, Liu HY, Lai T, Ma JL, Wang JF, Zhu YH: Evaluation of Lactobacillus rhamnosus GG using an Escherichia coli K88 model of piglet diarrhoea: Effects on diarrhoea incidence, faecal microflora and immune responses. Vet Microbiol 2010, 141:142-148.

10. Shu Q, Qu F, Gill HS: Probiotic treatment using Bifidobacterium lactis HN019 reduces weanling diarrhea associated with rotavirus and Escherichia coli infection in a piglet model. J Pediatr Gastroenterol Nutr 2001, 33:171-177.

11. Gibson GR, Probert HM, Loo JV, Rastall RA, Roberfroid MB: Dietary modulation of the human colonic microbiota: updating the concept of prebiotics. Nutr Res Rev 2004, 17:259-275.

12. Patterson JK, Yasuda K, Welch RM, Miller DD, Lei XG: Supplemental dietary inulin of variable chain lengths alters intestinal bacterial populations in young pigs. J Nutr 2010, 140:2158-2161.

13. Russell WR, Hoyles L, Flint HJ, Dumas ME: Colonic bacterial metabolites and human health. Curr Opin Microbiol 2013, 16:246-254.

14. Gantois I, Ducatelle R, Pasmans F, Haesebrouck F, Hautefort I, Thompson A, Hinton JC, Van Immerseel F: Butyrate specifically down-regulates Salmonella pathogenicity island 1 gene expression. Appl Environ Microbiol 2006, 72:946-949.

15. Tzortzis G, Goulas AK, Gee JM, Gibson GR: A novel galactooligosaccharide mixture increases the bifidobacterial population numbers in a continuous in vitro fermentation system and in the proximal colonic contents of pigs in vivo. J Nutr 2005, 135:1726-1731.

16. Mikkelsen LL, Jensen BB: Effect of fructo-oligosaccharides and transgalacto-oligosaccharides on microbial populations and microbial activity in the gastrointestinal tract of piglets post-weaning. Anim Feed Sci Technol 2004, 117:107-119.

17. Mountzouris KC, Balaskas C, Fava F, Tuohy KM, Gibson GR, Fegeros K: Profiling of composition and metabolic activities of the colonic microflora of growing pigs fed diets supplemented with prebiotic oligosaccharides. Anaerobe 2006, 12:178-185.

18. Bird AR, Vuaran M, Crittenden R, Hayakawa T, Playne MJ, Brown IL, Topping DL: Comparative effects of a high-amylose starch and a fructooligosaccharide on fecal bifidobacteria numbers and short-chain fatty acids in pigs fed Bifidobacterium animalis. Dig Dis Sci 2009, 54:947-954. 
19. Bomba A, Nemcova R, Gancarcikova S, Herich R, Guba P, Mudronova D: Improvement of the probiotic effect of micro-organisms by their combination with maltodextrins, fructo-oligosaccharides and polyunsaturated fatty acids. Br J Nutr 2002, 88(Suppl 1):95-99.

20. Nemcova R, Bomba A, Gancarcikova S, Reiffova K, Guba P, Koscova J, Jonecova Z, Scirankova L, Bugarsky A: Effects of the administration of lactobacilli, maltodextrins and fructooligosaccharides upon the adhesion of $E$. coli O8:K88 to the intestinal mucosa and organic acid levels in the gut contents of piglets. Vet Res Commun 2007, 31:791-800.

21. Gaggia F, Mattarelli P, Biavati B: Probiotics and prebiotics in animal feeding for safe food production. Int J Food Microbio/ 2010, 141(Suppl 1):15-28.

22. Gibson GR, Roberfroid MB: Dietary modulation of the human colonic microbiota: introducing the concept of prebiotics. J Nutr 1995, 125:1401-1412.

23. Biavati B, Mattarelli P: Genus I. Bifidobacterium. In Bergey's Manual of Systematic Bacteriology The Actinobacteria. Volume 5. 2nd edition. Edited by Whitman WB, Kämpfer P, Goodfellow M, Garrity GM, Ludwig W. New York: Springer Verlag; 2009:171-206.

24. Zihler A: In Vitro Assessment of Bacteriocinogenic Probiotics for Prevention and Treatment of Salmonella in Children using Novel In Vitro Continuous Colonic Fermentation and Cellular Models, PhD thesis. ETH Zurich, Department of Health Sciences and Technology; 2010.

25. von Ah U: Identification of Bifidobacterium Thermophilum RBL67 Isolated from Baby Feces and Partial Purification of its Bacteriocin, PhD thesis. ETH Zurich, Department of Health Sciences and Technology; 2006.

26. Toure R, Kheadr E, Lacroix C, Moroni O, Fliss I: Production of antibacterial substances by bifidobacterial isolates from infant stool active against Listeria monocytogenes. J Appl Microbiol 2003 95:1058-1069.

27. Zihler A, Le Blay G, Chassard C, Braegger C, Lacroix C: Bifidobacterium thermophilum RBL67 inhibits S. Typhimurium in an in vitro model of Salmonella infection in children. J Food Nutr Disord 2014, in press. 10.4172/2324-9323.S1-003.

28. Moroni $\mathrm{O}$, Kheadr E, Boutin Y, Lacroix C, Fliss I: Inactivation of adhesion and invasion of food-borne Listeria monocytogenes by bacteriocin-producing Bifidobacterium strains of human origin. Appl Environ Microbiol 2006, 72:6894-6901

29. Zihler A, Gagnon M, Chassard C, Lacroix C: Protective effect of probiotics on Salmonella infectivity assessed with combined in vitro gut fermentation-cellular models. BMC Microbiol 2011, 11:264.

30. Zihler A, Gagnon M, Chassard C, Hegland A, Stevens MJ, Braegger CP, Lacroix C: Unexpected consequences of administering bacteriocinogenic probiotic strains for Salmonella populations, revealed by an in vitro colonic model of the child gut. Microbiology 2010, 156:3342-3353.

31. von Ah U, Mozzetti V, Lacroix C, Kheadr EE, Fliss I, Meile L: Classification of a moderately oxygen-tolerant isolate from baby faeces as Bifidobacterium thermophilum. BMC Microbiol 2007, 7:79.

32. Payne AN, Zihler A, Chassard C, Lacroix C: Advances and perspectives in in vitro human gut fermentation modeling. Trends Biotechnol 2012, 30:17-25.

33. Tanner SA, Zihler Berner A, Rigozzi E, Grattepanche F, Chassard C, Lacroix C: In vitro continuous fermentation model (PolyFermS) of the swine proximal colon for simultaneous testing on the same gut microbiota. PLOS ONE 2014, 9:e94123.

34. Le Blay G, Rytka J, Zihler A, Lacroix C: New in vitro colonic fermentation model for Salmonella infection in the child gut. FEMS Microbiol Ecol 2009, 67:198-207

35. de Busser EV, de Zutter L, Dewulf J, Houf K, Maes D: Salmonella control in live pigs and at slaughter. Vet $J$ 2013, 196:20-27.

36. Hai DNN, Yuk HG: Changes in resistance of Salmonella Typhimurium biofilms formed under various conditions to industrial sanitizers. Food Control 2013, 29:236-240.

37. Hippe H, Hagelstein A, Kramer I, Swiderski J, Stackebrandt E: Phylogenetic analysis of Formivibrio citricus, Propionivibrio dicarboxylicus, Anaerobiospirillum thomasii, Succinimonas amylolytica and Succinivibrio dextrinosolvens and proposal of Succinivibrionaceae fam. nov. Int I Syst Bacteriol 1999, 49:779-782.

38. Stecher B, Chaffron S, Kappeli R, Hapfelmeier S, Freedrich S, Weber TC, Kirundi J, Suar M, McCoy KD, von Mering C, Macpherson AJ, Hardt WD: Like will to like: abundances of closely related species can predict susceptibility to intestinal colonization by pathogenic and commensal bacteria. PLoS Pathog 2010, 6:e1000711.
39. Adams MR, Hall CJ: Growth-inhibition of foodborne pathogens by lactic and acetic-acids and their mixtures. Int J Food Sci Technol 1988, 23:287-292.

40. Wilson PD, Wilson DR, Brocklehurst TF, Coleman HP, Mitchell G, Waspe CR Jukes SA, Robins MM: Batch growth of Salmonella typhimurium LT2: stoichiometry and factors leading to cessation of growth. Int J Food Microbiol 2003, 89:195-203.

41. van der Wielen PW, Biesterveld S, Lipman LJ, van Knapen F: Inhibition of a glucose-limited sequencing fed-batch culture of Salmonella enterica serovar Enteritidis by volatile fatty acids representative of the ceca of broiler chickens. Appl Environ Microbiol 2001, 67:1979-1982.

42. Kogan $G$, Kocher A: Role of yeast cell wall polysaccharides in pig nutrition and health protection. Livest Sci 2007, 109:161-165.

43. Tsukahara T, Iwasaki Y, Nakayama K, Ushida K: Stimulation of butyrate production in the large intestine of weaning piglets by dietary fructooligosaccharides and its influence on the histological variables of the large intestinal mucosa. J Nutr Sci Vitaminol (Tokyo) 2003, 49:414-421.

44. van der Meulen R, Adriany T, Verbrugghe K, De Vuyst L: Kinetic analysis of bifidobacterial metabolism reveals a minor role for succinic acid in the regeneration of $\mathrm{NAD}+$ through its growth-associated production. Appl Environ Microbiol 2006, 72:5204-5210.

45. Levine UY, Looft T, Allen HK, Stanton TB: Butyrate-producing bacteria, including mucin degraders, from the swine intestinal tract. Appl Environ Microbiol 2013, 79:3879-3881.

46. Le Blay G, Chassard C, Baltzer S, Lacroix C: Set up of a new in vitro model to study dietary fructans fermentation in formula-fed babies. $\mathrm{Br} J \mathrm{Nutr}$ 2010, 103:403-411.

47. Martinez RC, Cardarelli HR, Borst W, Albrecht S, Schols H, Gutierrez OP, Maathuis AJ, de Melo Franco BD, De Martinis EC, Zoetendal EG, Venema K, Saad SM, Smidt H: Effect of galactooligosaccharides and Bifidobacterium animalis Bb-12 on growth of Lactobacillus amylovorus DSM 16698, microbial community structure, and metabolite production in an in vitro colonic model set up with human or pig microbiota. FEMS Microbiol Ecol 2013, 84:110-123.

48. Flickinger EA, Van Loo J, Fahey GC Jr: Nutritional responses to the presence of inulin and oligofructose in the diets of domesticated animals: a review. Crit Rev Food Sci Nutr 2003, 43:19-60.

49. van der Meulen $R$, Makras $L$, Verbrugghe $K$, Adriany $T$, De Vuyst $L$ : In vitro kinetic analysis of oligofructose consumption by Bacteroides and Bifidobacterium spp. indicates different degradation mechanisms. Appl Environ Microbiol 2006, 72:1006-1012.

50. Martin-Pelaez S, Gibson GR, Martin-Orue SM, Klinder A, Rastall RA, La Ragione RM, Woodward MJ, Costabile A: In vitro fermentation of carbohydrates by porcine faecal inocula and their influence on Salmonella Typhimurium growth in batch culture systems. FEMS Microbiol Ecol 2008, 66:608-619.

51. Scott KP, Martin JC, Duncan SH, Flint HJ: Prebiotic stimulation of human colonic butyrate-producing bacteria and bifidobacteria, in vitro. FEMS Microbiol Ecol 2013, 87:30-40.

52. Morita H, Shiratori C, Murakami M, Takami H, Toh H, Kato Y, Nakajima F, Takagi M, Akita H, Masaoka T, Hattori M: Sharpea azabuensis gen. nov., sp. nov., a Gram-positive, strictly anaerobic bacterium isolated from the faeces of thoroughbred horses. Int J Syst Evol Microbio/ 2008, 58:2682-2686.

53. Salvetti E, Felis GE, Dellaglio F, Castioni A, Torriani S, Lawson PA: Reclassification of Lactobacillus catenaformis (Eggerth 1935) Moore and Holdeman 1970 and Lactobacillus vitulinus Sharpe et al. 1973 as Eggerthia catenaformis gen. nov., comb. nov. and Kandleria vitulina gen. nov., comb. nov., respectively. Int J Syst Evol Microbiol 2011, 61:2520-2524.

54. Buzoianu SG, Walsh MC, Rea MC, O'Sullivan O, Cotter PD, Ross RP, Gardiner GE, Lawlor PG: High-throughput sequence-based analysis of the intestinal microbiota of weanling pigs fed genetically modified MON810 maize expressing Bacillus thuringiensis Cry1 Ab (Bt maize) for 31 days. Appl Environ Microbiol 2012, 78:4217-4224.

55. Walsh MC, Buzoianu SG, Rea MC, O'Donovan O, Gelencser E, Ujhelyi G, Ross RP, Gardiner GE, Lawlor PG: Effects of feeding Bt MON810 maize to pigs for 110 days on peripheral immune response and digestive fate of the cry1Ab gene and truncated Bt toxin. PLOS ONE 2012, 7:e36141.

56. Fleissner CK, Huebel N, Abd El-Bary MM, Loh G, Klaus S, Blaut M: Absence of intestinal microbiota does not protect mice from diet-induced obesity. Br J Nutr 2010, 104:919-929.

57. Kararli $\Pi$ : Comparison of the gastrointestinal anatomy, physiology, and biochemistry of humans and commonly used laboratory animals. Biopharm Drug Dispos 1995, 16:351-380. 
58. Leser TD, Amenuvor JZ, Jensen TK, Lindecrona RH, Boye M, Moller K: Culture-independent analysis of gut bacteria: the pig gastrointestinal tract microbiota revisited. Appl Environ Microbiol 2002, 68:673-690.

59. Dostal A, Fehlbaum S, Chassard C, Zimmermann MB, Lacroix C: Low iron availability in continuous in vitro colonic fermentations induces strong dysbiosis of the child gut microbial consortium and a decrease in main metabolites. FEMS Microbiol Ecol 2013, 83:161-175.

60. Mathys S, Lacroix C, Mini R, Meile L: PCR and real-time PCR primers developed for detection and identification of Bifidobacterium thermophilum in faeces. BMC Microbiol 2008, 8:179.

61. Jost T, Lacroix C, Braegger C, Chassard C: Assessment of bacterial diversity in breast milk using culture-dependent and culture-independent approaches. Br J Nutr 2013, 110:1253-1262.

62. Wang Q, Garrity GM, Tiedje JM, Cole JR: Naive Bayesian classifier for rapid assignment of rRNA sequences into the new bacterial taxonomy. Appl Environ Microbiol 2007, 73:5261-5267.

doi:10.1186/s13099-014-0044-y

Cite this article as: Tanner et al:: Synergistic effects of Bifidobacterium thermophilum RBL67 and selected prebiotics on inhibition of Salmonella colonization in the swine proximal colon PolyFermS model. Gut Pathogens 2014 6:44.

\section{Submit your next manuscript to BioMed Central and take full advantage of:}

- Convenient online submission

- Thorough peer review

- No space constraints or color figure charges

- Immediate publication on acceptance

- Inclusion in PubMed, CAS, Scopus and Google Scholar

- Research which is freely available for redistribution 